\title{
The effects of climate factors on scabies. A 14-year population-based study in Taiwan
}

\author{
Jui-Ming Liu ${ }^{1}$, Hsiao-Wei Wang ${ }^{2,3}$, Fung-Wei Chang ${ }^{4}$, Yueh-Ping Liu ${ }^{5}$, Feng-Hsiang Chiu ${ }^{6,7}$,
} Yi-Chun Lin ${ }^{8}$, Kuan-Chen Cheng ${ }^{9,10}$, and Ren-Jun Hsu ${ }^{11,12,13, *}$

1 Division of Urology, Department of Surgery, Taoyuan General Hospital, Ministry of Health and Welfare, 330 Taoyuan, Taiwan

2 Division of Infectious Diseases, Department of Internal Medicine, School of Medicine, College of Medicine,

Taipei Medical University, 110 Tapei, Taiwan

3 Division of Infection Diseases, Department of Internal Medicine, Shuang Ho Hospital, Taipei Medical University, 235 Tapei, Taiwan

4 Department of Obstetrics \& Gynecology, Tri-Service General Hospital, National Defense Medical Center, 114 Tapei, Taiwan

5 Department of Emergency Medicine, National Taiwan University Hospital, 100 Tapei, Taiwan

6 Department of Emergency Medicine, Shuang Ho Hospital, Taipei Medical University, 235 Tapei, Taiwan

7 Superintendent Office, Ningbo Medical Center, Lihuili Eastern Hospital, Ningbo City, 315000 Zhejiang Province, PR China

8 Department of Internal Medicine, Lo-Hsu Medical Foundation, Lotung Poh-Ai Hospital, 265 Luodong, Taiwan

9 Graduate Institute of Food Science and Technology, National Taiwan University, 106 Tapei, Taiwan

${ }^{10}$ Institute of Biotechnology, National Taiwan University, 106 Tapei, Taiwan

11 Graduate Institute of Life Sciences, National Defense Medical Center, 114 Tapei, Taiwan

12 Department of Pathology and Graduate Institute of Pathology and Parasitology, the Tri-Service General Hospital, National Defense Medical Center, 114 Tapei, Taiwan

13 Biobank Management Center of the Tri-Service General Hospital, National Defense Medical Center, 114 Tapei, Taiwan

Received 4 August 2016, Accepted 20 November 2016, Published online 1 December 2016

\begin{abstract}
Scabies is a common infectious disease and can cause severe outbreaks if not controlled quickly. Besides personal contact history, environmental factors are also important. This study analyzed the effects of environmental climate factors on the incidence of scabies in Taiwan. We conducted a 14-year nationwide population-based study: a total of 14,883 patients with scabies infestation were enrolled. Monthly climate data were collected from Taiwan's Central Weather Bureau, including data on temperature, relative humidity, total rainfall, total rain days, and total sunshine hours. The linear relationships between these climate factors and scabies infestations or other risk factors were examined by Pearson's correlation analysis. Overall, the incidence of scabies was negatively correlated with temperature $(\gamma=-0.152, p<0.001)$, while being positively correlated with humidity $(\gamma=0.192, p<0.001)$. This useful information may provide evidence for lowering humidity at nursing facilities, hospitals, and military camps with scabies infestations, which may help to reduce its spread and prevent outbreaks.
\end{abstract}

Key words: Climate, Scabies, Taiwan, Population studies, National Health Insurance Research Database.

Résumé - Les effets des facteurs climatiques sur la gale. Une étude de 14 ans sur la population à Taiwan. La gale est une maladie infectieuse courante et peut causer des épidémies sévères si elle n'est pas contrôlée rapidement. Outre l'historique de contact personnel, les facteurs environnementaux sont également importants. Cette étude a analysé les effets des facteurs climatiques environnementaux sur l'incidence de la gale à Taiwan. Nous avons mené une étude nationale de 14 ans sur la population: un total de 14883 patients atteints d'infestation par la gale ont été enrôlés. Les données mensuelles sur le climat ont été recueillies auprès du Bureau Central Météorologique de Taiwan, y compris la température, l'humidité relative, les précipitations totales, le total des jours de pluie et le total d'heures d'ensoleillement. Les relations linéaires entre ces facteurs climatiques et les infestations de gale ou d'autres facteurs de risque ont été examinées par l'analyse de corrélation de Pearson. Dans l'ensemble, l'incidence de la gale était corrélée négativement à la température $(\gamma=-0.152, p<0.001)$, tout en étant positivement corrélée à l'humidité relative $(\gamma=0.192, p<0.001)$. Cette information utile peut fournir une indication pour abaisser l'humidité dans les établissements de soins infirmiers, les hôpitaux et les camps militaires avec des infestations de gale, ce qui peut aider à réduire sa propagation et prévenir les épidémies.

\footnotetext{
*Corresponding author: hsurnai@gmail.com
}

This is an Open Access article distributed under the terms of the Creative Commons Attribution License (http://creativecommons.org/licenses/by/4.0), which permits unrestricted use, distribution, and reproduction in any medium, provided the original work is properly cited. 


\section{Introduction}

Scabies is an infectious disease that is common around the world, with a global prevalence of about 300 million cases (or about $5 \%$ of the world's population) per year [15]. Scabies is a kind of parasitic infection caused by the mite Sarcoptes scabiei variety hominis. Scabies is mostly transmitted by person-to-person contact, and many outbreaks have been reported in nursing homes, hospitals, and army facilities $[5,20]$. All persons who have had contact history with infected patients, especially family members or those who have engaged in sexual contact, should receive preventative treatment [10] since asymptomatic infestation is likely to lead to re-infestation of the index case who is highly symptomatic. As such, scabies infestations increase financial burden in terms of medical resources and public health efforts. Various types of people have been reported to be more susceptible to scabies infestations, including people who live in urban areas, immunocompromised persons, the elderly, and institutionalized patients $[12,29]$. Complications of scabies may also be found due to secondary bacterial infections [22].

Meanwhile, a variety of environmental factors also influence human health. Seasonal variations have been observed for a number of clinical diseases, including myocardial infarction and several infectious diseases [14]. Seasonal variations in the incidences of infectious diseases may be associated with the epidemiology of the prevalent pathogens, changes in environmental and meteorological parameters, and alterations in human behavior. Scabies infestations have also been found to exhibit seasonal variations, with infections being especially common in the winter [12].

Although previous studies have revealed seasonal fluctuations in the rate of scabies infestations [20], there is a lack of studies regarding how scabies infestations are affected by different climates. In the present study, we aimed to investigate the effect of various climate variables, such as temperature, humidity, and total rainfall, on the incidence of scabies infestations. To do so, we conducted a 14-year retrospective population-based study to evaluate the relationship between climate parameters and scabies.

\section{Materials and methods}

\section{Data sources and collection}

We conducted a nationwide population-based study using data from Taiwan's National Health Insurance Research Database (NHIRD). The NHIRD collects data from the National Health Insurance (NHI) program, which started in 1995 and covered $99.9 \%$ of the 23 million people in Taiwan as of the end of 2013 [18]. The NHIRD contains all the medical records of inpatients and outpatients, including demographic data such as sex, date of birth, location, and insured amount, as well as medical records of clinical visits, admissions, and clinical procedures. Specifically, we used the Longitudinal Health Insurance Database 2000 (LHID2000), a sub-dataset of the NHIRD, for this study. The LHID2000 contains data from January 2000 to December 2013 for a randomly selected sample of one million people out of the 23 million people included in the NHIRD in 2000 [9]. The LHID2000 and NHIRD have a similar demographic distribution and origin of population [21]. The clinical diagnoses were made by the International Classification of Diseases, 9th revision, Clinical Modification (ICD-9-CM) [27]. The weather data in this study were collected by Taiwan's Central Weather Bureau (CWB). The CWB monitors 27 weather stations throughout Taiwan, which includes the islands of Taiwan, Penghu, Kinmen, and Lienchiang. We used monthly weather data in this study, including data on temperatures (measured in degrees Celsius $\left({ }^{\circ} \mathrm{C}\right)$ ), relative humidity (recorded as a percentage $(\%)$ ), total rainfall (measured in millimeters $(\mathrm{mm})$ ), total rain days (recorded in days), and total sunshine hours (recorded in hours). In Taiwan, the spring season includes March, April, and May; the summer season includes June, July, and August; the fall season includes September, October, and November; and the winter season includes December, January, and February.

\section{Ethics}

This study was approved by the Institutional Review Board of the Tri-Service General Hospital (approval number: TSGHIRB NO. B-105-06). As this was a retrospective study and all data were anonymous, the Institutional Review Board department agreed that it was not necessary to obtain patient consent.

\section{Study population}

The study subjects were selected from the LHID2000 covering the period from January 2000 to December 2013. The selected study subjects were newly diagnosed with scabies infestation (ICD-9-CM 133.0) between 2000 and 2013 (Fig. 1). All such diagnoses of scabies infestations were made by physicians, and all the patients were prescribed anti-scabies oral or topical medication for treatment.

The exclusion criteria for the study were as follows: patients who were diagnosed before December 31, 2000, or after January 1, $2013(n=3768)$; and patients who were younger than 20 years old $(n=3839)$. In Taiwanese civil law, people in their 20th year are considered adults. In general, study populations of adult are able to be approved by the Institutional Review Board in Taiwan. Studies in populations under 20 years of age are difficult to approve by Institutional Review Boards in Taiwan. Given these criteria, there were a total of 14,883 patients with scabies infestations who were enrolled in this study. A given diagnosis of scabies was made according to the patient's history and a physical examination by a licensed physician. Typical physical examination findings for those diagnosed with scabies include the following: generalized itching sparing the face and head; severe pruritus at night; inflammatory pruritic papules at infected body sites, especially the finger webs, flexor part of the wrists, flexor part of the elbows, axillae, buttocks, genitalia, and (in female patients) the breasts; and burrows and nodules [10]. 


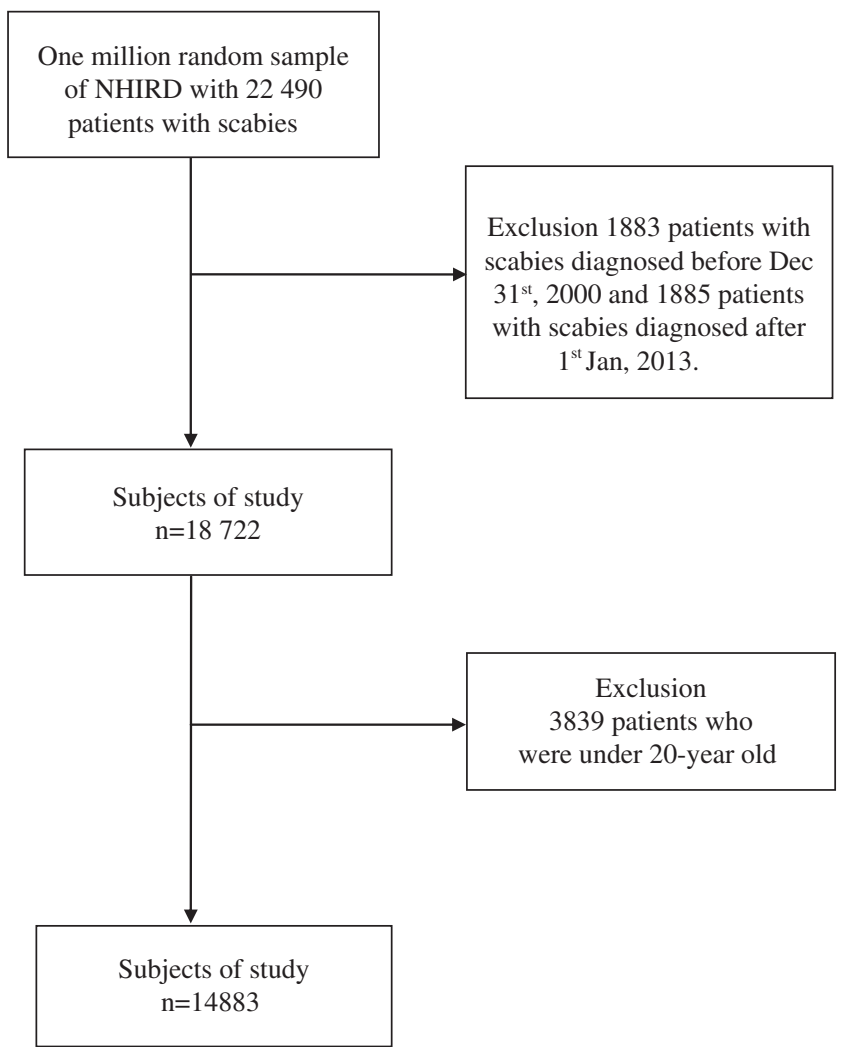

Figure 1. Flowchart of collection of study subjects of National Health Insurance Research Database (NHIRD), from January 2000 to December 2013.

\section{Variables}

The variables in this study were chosen on the basis of related studies in the past literature. Specifically, we selected the following variables: chronic pulmonary disease (ICD-9-CM 490-492, 494,496), diabetes mellitus (ICD-9-CM 250), hypertension (ICD-9-CM 401.1, 401.9), peptic ulcer disease (ICD-9-CM 533), mild liver disease (ICD-9-CM 571.2, 571.4-571.6), congestive heart failure (ICD-9-CM 428), rheumatologic disease (ICD-9-CM 714, 725-729), cerebrovascular disease (ICD-9-CM 430-438), malignancy (ICD-9-CM 140-208), Parkinson disease (ICD-9-CM 332), tuberculosis (ICD-9-CM 011,012), chronic kidney disease (ICD-9-CM 585,586,588), liver cirrhosis (ICD-9-CM: 571), hyperlipidemia (ICD-9-CM 272.4), heart disease (ICD-9-CM 393-398, 402, 404.0, 404.1, 404.9, 410-414, 415.0, 416.1, 416.8, 416.9, 420-429), anemia (ICD-9-CM 280-285), and epilepsy (ICD-9-CM 345). The monthly income levels of the study subjects were also taken from NHI program data and were categorized into the following four groups: $<20,000$ new Taiwan dollars (NTD); 20,000-40,000 NTD; 40,000-60,000 NTD; and $\geq 60,000$ NTD.

\section{Statistical analysis}

Descriptive statistical data for the study subjects and weather factors were calculated by the Microsoft ${ }^{\circledR} \mathrm{SQL}$ Server $^{\circledR}$ 2008. Further data analysis was conducted using
Table 1. Demographic characteristics of patients with scabies in Taiwan, from 2000 to 2013 .

\begin{tabular}{|c|c|c|}
\hline Characteristics & Scabies infected cases, $n$ & $\%$ \\
\hline No. of cases & $14883(100.0 \%)$ & \\
\hline Age (mean $\pm \mathrm{SD}$, years) & $52.4 \pm 21.0$ & \\
\hline $20-29$ & 2831 & 19.0 \\
\hline $30-39$ & 2190 & 14.7 \\
\hline $40-49$ & 2259 & 15.2 \\
\hline $50-59$ & 2065 & 13.9 \\
\hline $60-69$ & 1537 & 10.3 \\
\hline$\geq 70$ & 4001 & 26.9 \\
\hline \multicolumn{3}{|l|}{ Sex } \\
\hline Female & 7026 & 47.2 \\
\hline Male & 7857 & 52.8 \\
\hline \multicolumn{3}{|l|}{ Comorbidity disease* } \\
\hline Chronic pulmonary disease & 3054 & 20.5 \\
\hline Diabetes & 2396 & 16.1 \\
\hline Hypertension & 4905 & 33.0 \\
\hline Peptic ulcer disease & 2502 & 16.8 \\
\hline Mild liver disease & 1113 & 7.5 \\
\hline Congestive heart failure & 808 & 5.4 \\
\hline Rheumatologic disease & 667 & 4.5 \\
\hline Cerebrovascular disease & 2773 & 18.6 \\
\hline Malignancy & 572 & 3.8 \\
\hline Parkinson disease & 808 & 5.4 \\
\hline Tuberculosis & 522 & 3.5 \\
\hline Chronic kidney disease & 223 & 1.5 \\
\hline Liver cirrhosis & 1294 & 8.7 \\
\hline Hyperlipidemia & 901 & 6.1 \\
\hline Heart disease & 3672 & 24.7 \\
\hline Anemia & 1169 & 7.9 \\
\hline Epilepsy & 420 & 2.8 \\
\hline \multicolumn{3}{|l|}{ Insured amount (NTD) } \\
\hline$<20,000$ & 4385 & 29.5 \\
\hline $20,000-40,000$ & 7656 & 51.4 \\
\hline $40,000-60,000$ & 2012 & 13.5 \\
\hline$\geqq 60,000$ & 830 & 5.6 \\
\hline \multicolumn{3}{|l|}{ Insured region in Taiwan } \\
\hline Northern & 6569 & 44.1 \\
\hline Middle & 3374 & 22.7 \\
\hline Southern & 4363 & 29.3 \\
\hline Eastern and outlying islands & 577 & 3.9 \\
\hline
\end{tabular}

* Any kind of 17 comorbidities.

$\mathrm{NTD}=$ New Taiwan Dollar USD/TWD $\fallingdotseq 33$.

IBM SPSS statistics software, version 20 (IBM SPSS, 2013). Linear correlations between the weather factors and the incidence of scabies were calculated by Pearson's correlation method. A two-sided $p$-value $<0.05$ was regarded as statistically significant in all statistical tests.

\section{Results}

A total of 14,883 patients diagnosed with scabies infestations from 2000 to 2013 in Taiwan were included in this study. The demographic characteristics and medical conditions of the study subjects are shown in Table 1 . The mean age of the patients with scabies was $52.4 \pm 21.0$ years, and two age groups were predominant: patients older than 
Table 2. Average monthly mean meteorological factors in Taiwan from 2000 to 2013.

\begin{tabular}{|c|c|c|c|c|c|c|c|}
\hline \multirow[t]{2}{*}{ Month } & \multicolumn{3}{|c|}{ Temperature $\left({ }^{\circ} \mathrm{C}\right)$} & \multirow[t]{2}{*}{ Total sunshine hours } & \multirow[t]{2}{*}{ Relative humidity (\%) } & \multirow[t]{2}{*}{ Total rainfall $(\mathrm{mm})$} & \multirow[t]{2}{*}{ Total rain days } \\
\hline & Mean & $\operatorname{Max}$ & Minimum & & & & \\
\hline January & 16.90 & 21.90 & 10.60 & 128.48 & 75.95 & 62.23 & 8.29 \\
\hline February & 18.17 & 23.50 & 10.80 & 125.81 & 77.64 & 66.78 & 7.78 \\
\hline March & 19.79 & 24.30 & 12.80 & 139.23 & 75.42 & 77.97 & 9.50 \\
\hline April & 22.94 & 26.80 & 17.10 & 128.83 & 77.24 & 108.26 & 10.84 \\
\hline May & 25.86 & 28.70 & 20.50 & 160.26 & 77.85 & 213.51 & 12.09 \\
\hline June & 27.52 & 29.80 & 21.60 & 167.20 & 79.31 & 315.79 & 13.80 \\
\hline July & 28.72 & 30.80 & 22.50 & 223.84 & 77.14 & 291.61 & 11.28 \\
\hline August & 28.48 & 30.10 & 22.30 & 196.28 & 78.31 & 347.25 & 13.52 \\
\hline September & 27.39 & 30.00 & 21.20 & 171.50 & 77.44 & 283.08 & 11.52 \\
\hline October & 24.92 & 28.00 & 19.00 & 175.30 & 73.97 & 101.41 & 6.51 \\
\hline November & 22.06 & 25.60 & 16.90 & 139.00 & 75.03 & 95.65 & 7.87 \\
\hline December & 18.41 & 22.90 & 11.60 & 137.63 & 73.73 & 71.05 & 7.39 \\
\hline
\end{tabular}

70 years old $(26.9 \%)$ and patients $20-29$ years old $(19.0 \%)$. There were slightly more male patients than female patients, and the mean CCI index was $1.4 \pm 2.0$. The comorbidities most frequently linked with scabies infestations were hypertension, heart disease, chronic pulmonary disease, cerebrovascular disease, peptic ulcer disease, and diabetes. Patients with an insured amount between 20,000 and 40,000 NTD represented a higher percentage of the total $(51.4 \%)$ than those in other insured amount ranges.

The average monthly mean data for the various climate factors from 2000 to 2013 are shown in Table 2. Taiwan is located in the Western Pacific and has a subtropical climate. The climate data analyzed for this study included data on temperatures $\left({ }^{\circ} \mathrm{C}\right)$, total sunshine hours, relative humidity $(\%)$, total rainfall $(\mathrm{mm})$, and total rain days. The average monthly temperature was lowest $\left(16.9^{\circ} \mathrm{C}\right)$ in January and highest $\left(28.72{ }^{\circ} \mathrm{C}\right)$ in July. The average total sunshine hours were lowest (125.81) in February and highest (223.84) in July. The average monthly relative humidity in Taiwan ranged between $73 \%$ and $79 \%$. The average total rainfall and total rain days were both highest in the months of June, July, and August.

Correlations between the seasonal climate parameters and scabies from 2000 to 2013 in Taiwan are shown in Table 3. Overall, two climate parameters were significantly associated with the incidence of scabies. Specifically, average temperature was negatively correlated with the incidence of scabies $(\gamma=-0.152, \quad p<0.001)$, while relative humidity was positively correlated with the incidence of scabies $(\gamma=0.192, p<0.001)$. Table 3 also shows the relationships between the climate parameters and the incidence rates of scabies for the different seasons of the year. In spring, average temperature was negatively correlated with the incidence of scabies $(\gamma=-0.262, p<0.001)$, while total rainfall was positively correlated with the incidence of scabies $(\gamma=$ $0.212, p=0.011)$. In summer, the incidence of scabies was negatively correlated with total sunshine hours $(\gamma=-0.305$, $p<0.001$ ) and positively correlated with total rain days $(\gamma=0.190, p=0.022)$. In fall, the incidence of scabies was positively correlated with relative humidity $(\gamma=0.217$, $p=0.009)$. In winter, the incidence of scabies was negatively
Table 3. Correlation of seasonal climate parameters to scabies from 2000 to 2013 in Taiwan.

\begin{tabular}{|c|c|c|}
\hline \multirow[t]{2}{*}{$\begin{array}{l}\text { Average monthly climate } \\
\text { parameters }\end{array}$} & \multicolumn{2}{|c|}{$\begin{array}{c}\text { Incidence of scabies } \\
\text { infection } \\
\end{array}$} \\
\hline & $r$ & $p$ \\
\hline \multicolumn{3}{|l|}{$\overline{\text { All }}$} \\
\hline Temperature $\left({ }^{\circ} \mathrm{C}\right)$ & -0.152 & $<0.001 * * *$ \\
\hline Total sunshine hours & -0.059 & 0.155 \\
\hline Relative humidity (\%) & 0.192 & $<0.001 * * *$ \\
\hline Total rainfall amount $(\mathrm{mm})$ & 0.034 & 0.416 \\
\hline Total rain days & 0.046 & 0.272 \\
\hline \multicolumn{3}{|l|}{ Spring } \\
\hline Temperature $\left({ }^{\circ} \mathrm{C}\right)$ & -0.262 & $0.001 * *$ \\
\hline Total sunshine hours & 0.041 & 0.629 \\
\hline Relative humidity (\%) & 0.119 & 0.154 \\
\hline Total rainfall amount $(\mathrm{mm})$ & 0.212 & $0.011 *$ \\
\hline Total rain days & 0.094 & 0.261 \\
\hline \multicolumn{3}{|l|}{ Summer } \\
\hline Temperature $\left({ }^{\circ} \mathrm{C}\right)$ & 0.126 & 0.133 \\
\hline Total sunshine hours & -0.305 & $<0.001 * * *$ \\
\hline Relative humidity (\%) & -0.045 & 0.593 \\
\hline Total rainfall amount $(\mathrm{mm})$ & 0.098 & 0.241 \\
\hline Total rain days & 0.190 & $0.022 *$ \\
\hline \multicolumn{3}{|l|}{ Fall } \\
\hline Temperature $\left({ }^{\circ} \mathrm{C}\right)$ & -0.143 & 0.087 \\
\hline Total sunshine hours & 0.059 & 0.484 \\
\hline Relative humidity (\%) & 0.217 & $0.009^{*}$ \\
\hline Total rainfall amount $(\mathrm{mm})$ & -0.055 & 0.512 \\
\hline Total rain days & -0.022 & 0.792 \\
\hline \multicolumn{3}{|l|}{ Winter } \\
\hline Temperature $\left({ }^{\circ} \mathrm{C}\right)$ & -0.336 & $<0.001 * * *$ \\
\hline Total sunshine hours & 0.035 & 0.674 \\
\hline Relative humidity (\%) & 0.475 & $<0.001 * * *$ \\
\hline Total rainfall amount $(\mathrm{mm})$ & 0.317 & $<0.001 * * *$ \\
\hline Total rain days & 0.082 & 0.328 \\
\hline
\end{tabular}

$r$ : Pearson's correlation, ${ }^{* * *} p<0.001 ;{ }^{* *} p=0.001 ;{ }^{*} p<0.05$.

correlated with temperature $(\gamma=-0.336, p<0.001)$ and positively correlated with relative humidity $(\gamma=0.475$, $p<0.001)$ and total rainfall $(\gamma=0.317, p<0.001)$. 


\section{Discussion}

This is the first study to investigate the relationships between different climate parameters and the incidence of scabies in Taiwan. The results of this 14-year nationwide population-based study showed that the incidence of scabies was negatively correlated with average temperature and positively correlated with relative humidity.

Taiwan lies in the Western Pacific at the Tropic of Cancer, and the general climate of Taiwan ranges from marine subtropical to tropical. Temperature has been well established by previous research studies to be among the climate factors that influence the incidence of scabies. Scabies is a kind of parasitic infection caused by the mite Sarcoptes scabiei. Higher temperatures accelerate the desiccation and death of these mites [13]. In contrast, the mites have better survival and higher fertility rates in cool weather [4, 24], with the mite eggs being capable of remaining viable off of a host for up to 10 days at low temperatures [3]. Long-term observations from Scotland and Israel have demonstrated that the incidence of scabies in those countries was higher during cooler seasons, indicating that the increased person-to-person contact and overcrowding that occur in colder weather facilitate the spread of scabies [3, 20]. Consistent with these studies, our study also demonstrated a negative correlation between temperature and the rate of scabies infestations.

Previous studies have found that scabies mites can survive much longer (up to 19 days) in a cool and humid environment than under general indoor conditions (only 1.5 days) [3]. Relatedly, our study found that relative humidity was positively correlated with the rate of scabies infestations in Taiwan, implying that humid environments result in higher rates of scabies infestations.

Although we did not observe a significant seasonality trend in the incidence of scabies, seasonality trends for scabies infestations have been reported in a large population study of the Israeli Army (specifically, this study reported a higher incidence in winter than in summer) [20]. Many studies, in fact, have reported high incidences of scabies infestations during the cool weather of the fall and winter seasons $[1,25$, 26]. As such, we further investigated the relationships between climate parameters and scabies infestations according to the different seasons. In spring, average temperature was negatively correlated with the incidence of scabies, while total rainfall was positively correlated with the incidence of scabies. In fall, relative humidity was positively correlated with the incidence of scabies infestations. In winter, temperature was negatively correlated with the incidence of scabies, whereas relative humidity and total rainfall were positively correlated with the incidence of scabies. Taken together, these results suggest that the cool and humid weather typical of the aforementioned seasons was more suitable for the survival and fertility of the scabies mites. In summer, meanwhile, the incidence of scabies was positively correlated with total rainfall days and negatively correlated with total sunshine hours. Perhaps relatedly, human behaviors also play an important role in the incidence of scabies infestations. For example, the higher number of rainy days in summer in
Taiwan may cause people to stay inside, causing overcrowding and higher levels of contact with other people. This increased personal contact may, in turn, tend to result in more scabies infestations.

In our study, two age groups were predominant: patients older than 70 years of age and patients aged 20-29 years. A previous study in Northern Taiwan found that elderly patients with certain risk factors, such as being bedridden, living in a nursing home, poor clinical status on admission, and long-term use of a catheter, had higher rates of scabies infestations [28]. Other studies have also reported that immunocompromised persons, the elderly, and institutionalized patients face greater risks of scabies infestation [12, 29]. In underdeveloped countries, the incidence of scabies is higher in younger populations, whereas the prevalence is similar across all ages in developed nations [6, 8]. In Taiwan, most young male adults perform compulsory military service in their early $20 \mathrm{~s}$, meaning that they typically live together with other young males for one to two years. Perhaps related to this, the term "army itch" has been used in various countries for more than 100 years, with cases of this disease erupting during times of war. Investigations by experts have found that scabies infestations are the cause of this so-called "army itch" [11]. Related studies have also found that scabies infestations are particularly prevalent among those engaged in military service, especially in times of war [19, 23]. Moreover, the normal social activities of young infected adults, such as visits home or sexual activities, may facilitate the spread of scabies and cause community outbreaks $[16,19]$.

Scabies may be difficult to diagnose at the beginning of infection. Scabies infestation may be misdiagnosed as an adverse drug reaction [2], atopic dermatitis [17], contact dermatitis [17], Langerhans cell histiocytosis [7], or immunobullous disease [17]. Moreover, misdiagnoses may lead to serious consequences or even outbreaks. In this study, misdiagnoses of scabies may exist, leading to underestimation of the incidence of scabies. Even skin biopsy may also involve the possibility of misdiagnosis [2]. The diagnosis should be made on the basis of patient history and detailed physical examination of skin lesions. Definitive diagnosis requires the microscopic identification of mites or mite parts.

There are some limitations to this study. First, this is a retrospective population-based study. Second, the diagnoses of scabies among the study subjects were based only on physical examinations and patient histories, and young physicians may have made some misdiagnoses due to lack of experience. Third, the data for the climate parameters investigated were from 27 weather stations monitored by Taiwan's CWB, but these 27 stations did not cover every village and town in Taiwan. Given these limitations, further large prospective randomized studies are needed to investigate the relationships between climate parameters and scabies infestations.

Scabies is a worldwide problem. While scabies is a treatable disease with a low fatality rate, it is also highly contagious. Fortunately, early recognition of scabies can reduce the length of hospitalization, reduce ward closures for infection control, allow for early treatment of patients, and limit the cost of environmental disinfection procedures. In conclusion, this 
study found that average temperature was negatively correlated with the incidence of scabies, while relative humidity was positively correlated with incidence. As such, lowering humidity and elevating room temperature may help to reduce rates of scabies infestation. Accordingly, we suggest that room temperatures be raised while humidity levels are lowered in the event that suspected scabies patients are found in nursing facilities, hospitals, and military camps in order to potentially help prevent further spread of the disease. Knowledge of the climate factors predicting increased incidences of scabies may help health policy planners and physicians to release alerts under certain climate conditions, decrease the disease burden, and prevent further outbreaks in high-risk environments.

\section{Conflict of interest}

The authors declare no conflict of interest in relation with this paper.

Acknowledgements. This work was supported by grants from the Ministry of Science and Technology Taiwan (MOST 104-2320B-016-012-MY3), the Tri-Service General Hospital (TSGH-C105168, TSGH-C104-188), and the Taoyuan General Hospital, Ministry of Health and Welfare (10533) for the analysis of data.

The implications and conclusions do not represent the opinions of the Bureau of National Health Insurance, the Department of Health, or the National Health Research Institute.

\section{References}

1. Ahmed S, Aftabuddin AK. 1977. Common skin diseases (analysis of 7636 cases). Bangladesh Medical Research Council Bulletin, 3(1), 41-45.

2. Almond DS, Green CJ, Geurin DM, Evans S. 2000. Lesson of the week: Norwegian scabies misdiagnosed as an adverse drug reaction. British Medical Journal, 320(7226), 35-36.

3. Arlian LG, Runyan RA, Estes SA. 1984. Cross infestivity of Sarcoptes scabiei. Journal of the American Academy of Dermatology, 10(6), 979-986.

4. Arlian LG, Runyan RA, Achar S, Estes SA. 1984. Survival and infectivity of Sarcoptes scabiei var canis and var hominis. Journal of the American Academy of Dermatology, 11(2 Pt 1), 210-215.

5. Barrett NJ, Morse DL. 1993. The resurgence of scabies. Communicable disease report. CDR review, 3(2), 32-34.

6. Blumenthal DS, Taplin D, Schultz MG. 1976. A community out-break of scabies. American Journal of Epidemiology, 104(6), 667-672.

7. Burch JM, Krol A, Weston WL. 2004. Sarcoptes scabiei infestation misdiagnosed and treated as Langerhans cell histiocytosis. Pediatric Dermatology, 21(1), 58-62.

8. Burkart CG. 1983. Scabies: an epidemiologic reassessment. Annals of Internal Medicine, 98(4), 498-503.

9. Chang FW, Lee WY, Liu YP, Yang JJ, Chen SP, Cheng KC, Lin YC, Ho TW, Chiu FH, Hsu RJ, Liu JM. 2016. The relationship between economic conditions and postpartum depression in Taiwan: a nationwide population-based study. Journal of Affective Disorders, 204(1), 174-179.
10. Chosidow O. 2006. Scabies. New England Journal of Medicine, 354(16), 1718-1727.

11. Cropley TG. 2006. The "army itch:” A dermatological mystery of the American civil War. Journal of the American Academy of Dermatology, 55(2), 302-303.

12. Downs AM, Harvey I, Kennedy CT. 1999. The epidemiology of head lice and scabies in the UK. Epidemiology \& Infection, 122(3), 471-477.

13. Estes SA, Estes J. 1993. Therapy of scabies: nursing homes, hospitals, and the homeless. Seminars in Dermatology, 12(1), 26-33.

14. Falagas ME, Theocharis G, Spanos A, Vlara LA, Issaris EA, Panos G, Peppas G. 2008. Effect of meteorological variables on the incidence of respiratory tract infections. Respiratory Medicine, 102(5), 733-737.

15. Hengge UR, Currie BJ, Jäger G, Lupi O, Schwartz RA. 2006. Scabies: a ubiquitous neglected skin disease. Lancet Infectious Diseases, 6(12), 769-779.

16. Heukelbach J, Wilcke T, Winter B, Feldmeier H. 2005. Epidemiology and morbidity of scabies and pediculosis capitis in resource-poor communities in Brazil. British Journal of Dermatology, 153(1), 150-156.

17. Hicks MI, Elston DM. 2009. Scabies. Dermatology and Therapy, 22(4), 279-292.

18. Liu JM, Lin PH, Hsu RJ, Chang YH, Cheng KC, Pang ST, Lin SK. 2016. Complementary traditional Chinese medicine therapy improves survival in patients with metastatic prostate cancer. Medicine (Baltimore), 95(31), e4475.

19. Mimouni D, Gdalevich M, Mimouni FM, Haviv J, Ashkenazi I. 1998. The epidemiologic trends of scabies among Israeli soldiers: a 28-year follow-up. International Journal of Dermatology, 37(8), 586-587.

20. Mimouni D, Ankol OE, Davidovitch N, Gdalevich M, Zangvil E, Grotto I. 2003. Seasonality trends of scabies in a young adult population: a 20 -year follow-up. British Journal of Dermatology, 149(1), 157-159.

21. National Health Research Institutes. 2015. National Health Insurance Research Database (online). Available at: http:// nhird.nhri.org.tw/en/Data_Subsets.html\#S3. Accessed October $1,2015$.

22. Roberts LJ, Huffam SE, Walton SF, Currie BJ. 2005. Crusted scabies: clinical and immunological findings in seventy-eight patients and a review of the literature. Journal of Infection, 50(5), 375-381.

23. Savin JA. 2005. Scabies in Edinburgh from 1815 to 2000. Journal of the Royal Society of Medicine, 98(3), 124-129.

24. Sokolova TV, Radchenko MI, Lange AB. 1989. The seasonability of scabies morbidity and the fertility of the itch mite Sarcoptes scabei de Geer as an index of the activity of a population of the caucative agent. Vestnik Dermatologii i Venereologii, 11, 12-15.

25. Thieberge G. 1922. Sur les variations de fréquence de la gale. Bulletin de l'Académie Nationale de Médecine, 88, 52.

26. Tüzün Y, Kotoğyan A, Cenesizoğlu E, Baransü O, Ozarmağan G, Ural A, Cilara A, Gürler A, Tat AL. 1980. The epidemiology of scabies in Turkey. International Journal of Dermatology, 19(1), 41-44.

27. US Department of Health and Human Services, Public Health Service, Health Care Financing Administration. 1989. The International Classification of Diseases: 9th Revision, Clinical Modification: ICD-9-CM. 
28. Wang CH, Lee SC, Huang SS, Kao YC, See LC, Yang SH. 2012. Risk factors for scabies in Taiwan. Journal of Microbiology, Immunology and Infection, 45(4), 276-280.
29. Zafar AB, Beidas SO, Sylvester LK. 2002. Control of transmission of Norwegian scabies. Infection Control \& Hospital Epidemiology, 23(5), 278-279.

Cite this article as: Liu J-M, Wang H-W, Chang F-W, Liu Y-P, Chiu F-H, Lin Y-C, Cheng K-C \& Hsu R-J: The effects of climate factors on scabies. A 14-year population-based study in Taiwan. Parasite, 2016, 23, 54.

\section{-0 PARASTE}

An international open-access, peer-reviewed, online journal publishing high quality papers on all aspects of human and animal parasitology

Reviews, articles and short notes may be submitted. Fields include, but are not limited to: general, medical and veterinary parasitology; morphology, including ultrastructure; parasite systematics, including entomology, acarology, helminthology and protistology, and molecular analyses; molecular biology and biochemistry; immunology of parasitic diseases; host-parasite relationships; ecology and life history of parasites; epidemiology; therapeutics; new diagnostic tools.

All papers in Parasite are published in English. Manuscripts should have a broad interest and must not have been published or submitted elsewhere. No limit is imposed on the length of manuscripts.

Parasite (open-access) continues Parasite (print and online editions, 1994-2012) and Annales de Parasitologie Humaine et Comparée (1923-1993) and is the official journal of the Société Française de Parasitologie. 